\title{
POESIA E AS ESTRUTURAS ANTROPOLÓGICAS DO IMA- GINÁRIO DE GILBERT DURAND: leitura de um poema de Ferreira Gullar
}

\section{RESUMO}

Frente à falência dos grandes sistemas explicativos orientados pela razão (aristotélica ou cartesiana) que regeram a Modernidade, a partir da segunda metade do século XX, surgem diversas teorias que procuram uma reavaliação positiva da imagem, investigando e sistematizando o imaginário humano, individual e coletivo, outrora excluído das possibilidades de acesso ao conhecimento. O estruturalismo figurativo de Gilbert Durand, nesse contexto, traz ao cenário intelectual uma perspectiva consistente, instigante e profícua aos estudos do imaginário. Neste artigo, pretendemos apresentar alguns dos pressupostos da teoria de Gilbert Durand, assim como, um panorama geral das "estruturas antropológicas do imaginário". Além disso, a partir da leitura de um poema de Ferreira Gullar à luz da teoria durandiana, expomos algumas das possibilidades que a investigação do imaginário oferece à crítica literária.

PALAVRAS-CHAVE: Imaginário. Poesia. Gilbert Durand. Ferreira Gullar.

\section{Introdução}

Uma das primeiras abordagens teóricas sobre o caráter do objeto estético, conforme Compagnon (2010), encontra-se na obra Arte Poéti- 
ca de Aristóteles. Para o grego, a poesia era mimesis, representação de caráter imitativo da natureza, obra humana advinda do prazer sentido no ato de imitar. Nesse sentido, a literatura seria (re)presentação do mundo. Compagnon observa que o posicionamento aristotélico repercute nas posições teóricas da crítica literária humanista, realista, naturalista e mesmo marxista, que partem da possibilidade referencial da literatura de construir uma imagem autêntica do mundo. No sentido oposto, Compagnon posiciona a teoria literária pós-moderna que, orientada pelos posicionamentos de Saussure e Peirce quanto ao signo linguístico, defende a ideia de autorreferencialidade da literatura, isto é, a literatura como sistema de significações que se refere apenas a si mesma, nutrindo-se de um mundo intra e intertextual.

Em Saussure, a ideia do arbitrário do signo implica a autonomia relativa da língua em relação à realidade e supõe que a significação seja diferencial (resultando da relação entre os signos) e não referencial (resultando da relação entre as palavras e as coisas). Em Peirce, a ligação original entre o signo e seu objeto foi quebrada, perdida, e a série dos interpretantes caminha indefinidamente de signo em signo, sem nunca encontrar a origem, numa sèmiosis qualificada de ilimitada. Segundo esses dois precursores, pelo menos tal como a teoria literária os recebeu, o referente não existe fora da linguagem, mas é produzido pela significação, depende da interpretação (COMPAGNON, 2010, p. 97).

O mundo apresentado pela literatura, nessa perspectiva, promoveria, apenas, a ilusão de acesso à realidade, um "effet de réel", mas o texto literário não seria senão um mosaico de citações de outros textos.

Nosso maior crítico literário, Antonio Candido, aproxima-se da primeira ideia - a literatura como forma de (re)apresentação do "real". Candido (2000, p. 4), inclusive, caracteriza-a como sistema mediado pela cultura, observa que a literatura mantém laços indissociáveis com a sociedade; no entanto, destaca que não deve ser compreendida como mero reflexo do exterior, visto que a sociedade transforma-se no interior da obra literária em elemento constitutivo de sua estrutura interna - "o externo (no caso o social) importa não como causa, nem como significado, mas como elemento que desempenha um certo papel na constituição da estrutura, tornando-se, portanto, interno".

Adorno (1993), para citar outro exemplo, observa que a literatura atravessa a idiossincrasia do sujeito individual, posto que é um comportamento, e como tal, não pode ser isolado da expressão de um sujeito. 
Porém, a literatura rompe a reclusão idiossincrática e vai além da contingência existencial do autor, constituindo-se indissociável da sociedade, visto que "Toda a idiossincrasia, em virtude do seu momento mimético pré-individual, vive das forças coletivas, de que ela própria é inconsciente." (p. 56). Desdobrando-se a ideia, embora seja a literatura expressão de caráter individual, nela se imprime as condições sócio-históricas e ideológicas da qual participam autor e obra.

Candido e Adorno - autores que, de certa forma, mantêm uma relação com o materialismo histórico de Marx - postulam certa imbricação inexorável entre sociedade e literatura, e a necessidade de atentar ao momento histórico em que determinada obra foi escrita para uma compreensão mais efetiva dos sentidos que emanam do texto.

Neste artigo, observaremos que, em certo sentido, a pretensão teórica do estruturalismo figurativo de Gilbert Durand constitui-se sobre um escopo de maior abrangência. Para compreender os pressupostos que norteiam o imaginário de Durand, primeiramente, cabe salientar que a principal obra na qual é descrita a teoria, As estruturas antropológicas do imaginário (2002), embora cite diversas obras literárias, não é sobre teoria literária, mas uma obra de antropologia com a pretensão de compreender o pensamento humano em sua relação com a realidade exterior. Em segundo lugar, cabe observar que para Gilbert Durand, como para os demais autores citados nesse trabalho, a relação entre homem e "realidade" é sempre mediada. Isto é, diferentemente de outros animais em que os estímulos externos acarretam reações imediatas, a condição humana impõe um "processo interpretativo" na tradução mental da realidade exterior. Nesse ponto, a diferença fundamental entre Durand, Candido e Adorno é que, para o primeiro, a sociedade não é o elo único dessa mediação, mas parte de uma tríade de elementos que compõem o imaginário, esse sim, o elo que une homem e realidade exterior - "existe, no nível imaginário, uma troca incessante das pulsões subjetivas e assimiladoras com as intimidações objetivas que emanam do meio cósmico e social" (MELLO, 2002, p. 77). Por fim, cabe demonstrar que a teoria sobre as estruturas antropológicas de Gilbert Durand pode ser um interessante aporte para a interpretação e crítica literária.

Para tal fim, organizamos este artigo em três partes. Na primeira, realizamos uma breve apresentação da teoria do imaginário de Gilbert Durand. Em seguida, interpretamos um poema de Ferreira Gullar da obra Em algum parte alguma (2010) a partir do imaginário de Durand. Por fim, 
consideramos os pontos positivos da teoria durandiana para a compreensão do fenômeno estético.

\section{0 imaginário de Gilbert Durand}

\subsection{Alguns pressupostos do pensamento de Gilbert Durand}

Para compreendermos a teoria de Gilbert Durand é necessário, primeiramente, observar que, de certo modo, o autor parte de uma compreensão materialista do ser humano; no entanto, tal compreensão não é restrita apenas às condições sócio-históricas e ambientais nas quais os homens estão imersos, mas também imbricada com as condições biológicas que orientam a ação do homem no mundo. Desse modo, as estruturas biopsíquicas do ser humano, o meio cósmico e o meio social são os três elementos que compõem as complexas estruturas do imaginário humano, responsáveis, por sua vez, pelos processos de engendramento dos sentidos atribuídos à realidade pelo homem.

Para melhor esclarecer o ponto de partida de Durand, podemos compará-lo aos pressupostos que norteiam o pensamento de outros dois teóricos que fundaram perspectivas surpreendentemente consistentes e reveladoras da psique e da sociedade humanas, assim como, contribuíram para a constituição e desenvolvimento de diversas áreas do conhecimento, Freud e Marx.

O pressuposto fundamental do materialismo histórico de Karl Marx é que a produção econômica (infraestrutura) determina a estrutura social, política e intelectual de cada época, e o motor que promove as mudanças na infraestrutura das sociedades é a luta de classes, decorrente das contradições surgidas no seio da produção econômica. Em outras palavras, Para Marx, a compreensão da sociedade humana não pode partir, por exemplo, do trajeto introspectivo de um racionalismo cartesiano, pois são as condições materiais existentes na sociedade que determinam tanto as diferentes formas de sociabilidade quanto as ideias que circulam em determinada época.

O resultado geral a que cheguei e que, uma vez obtido, serviu de fio condutor aos meus estudos, pode resumir-se assim: na produção social da sua vida, os homens contraem determinadas relações necessárias e independentes da sua vontade, relações de produção que correspondem a uma determinada fase de desenvolvimento das suas forças produtivas materiais. O conjunto dessas relações de produção forma a estrutura 
econômica da sociedade, a base real sobre a qual se levanta a superestrutura jurídica e política e a qual correspondem determinadas formas de consciência social. O modo de produção da vida material condiciona o processo da vida social, política e espiritual em geral. Não é a consciência do homem que determina o seu ser, mas, pelo contrário, o seu ser social é que determina sua consciência. (Marx, 1983, p. 17)

Dessa forma, podemos observar que o pensamento de Marx não parte da consciência individual do homem, nem atenta ao conjunto de imagens que constituem o universo humano e os seus significados, pois a sociedade e o homem, para o autor, são resultados das relações produtivas.

Sigmund Freud, ao contrário de Marx, não parte da sociedade para compreender o homem e suas relações sociais, mas da psique humana. Para Freud, a causa de grande parte dos incidentes (psíquicos e, até mesmo, certos incidentes fisiológicos) que determinam as ações do indivíduo provém da psique, e o motor que propulsiona a psique é a libido (força sexual). Para Freud, a psique é espécie de reservatório da biografia completa do indivíduo; no entanto, apenas uma pequena parte desse reservatório é acessível à consciência humana, sendo a maior parte inacessível, esta denominada de inconsciente. No inconsciente, entre outros elementos, são armazenados interditos oriundos do embate entre a necessidade irreprimível de satisfação da libido e a contrapulsão da censura que frustra a satisfação libidinal. Entretanto, Freud observa que a contrapulsão da censura frustra apenas a satisfação direta da libido, mas não é capaz de neutralizar a força libidinal. Consequentemente, a libido manifestar-se-á por meio de vias marginais, e esses caminhos alternativos resultantes dos bloqueios da libido são figurativizados nas imagens. Desse modo, a compreensão da relação entre psiquismo humano e pulsão libidinal é fundamental para a compreensão do indivíduo na teoria freudiana, e é a interpretação das imagens (geralmente oníricas) que possibilita decifrar como a pulsão libidinal, a contrapulsão da censura, as causas da censura e os interditos recalcados no inconsciente pela censura constituem cada indivíduo.

Em outras palavras, para Marx, a consciência humana é determinada pela sociedade e o imaginário não exerce papel algum na constituição. Para Freud, a consciência humana é determinada pelo embate entre a pulsão libidinal e a contrapulsão da censura, e o imaginário é figurativização desse processo. $\mathrm{O}$ estruturalismo figurativo de Gilbert Durand, por sua vez, observa que ambas as teorias chegaram à epifenômenos do processo 
intelectivo humano, visto que, para Durand, não são apenas as condições materiais e decorrentes pedagogias constituídas nas sociedades e nem apenas a força da libido sexual capazes de desvelar a forma como homem e realidade exterior interagem na constituição dos sentidos; mas a relação entre os complementos pedagógicos exigidos pela neotenia humana e as raízes inatas da representação. Ou seja, o homem nasce com o desenvolvimento físico e mental incompleto, logo, necessita de um movimento de complementaridade entre as aptidões inatas e as interpelações do meio cósmico e das formas de socialidade, ideologias, pedagogias, códigos de conduta e zonas de estratificação que emolduram e restringem as possibilidades de expressão e ação humanas. Desse modo, o que move o processo intelectivo humano é o imaginário oriundo dessa tríplice relação, e cada imagem é constituída por aquilo que Durand denominou de "trajeto antropológico".

O 'trajeto antropológico' representa a afirmação na qual o símbolo deve participar de forma indissolúvel para emergir numa espécie de 'vaivém' contínuo nas raízes inatas da representação do sapiens e, na outra 'ponta', nas várias interpelações do meio cósmico e social. Na formulação do imaginário, a lei do 'trajeto antropológico', típica de uma lei sistêmica, mostra muito bem a complementaridade existente entre o status das aptidões inatas do sapiens, a repartição dos arquetípicos verbais nas estruturas 'dominantes' e os complementos pedagógicos exigidos pela neotenia humana. (DURAND, 2004, p. 90)

O imaginário é o elo obrigatório entre o sentido e a experiência sensível, o conjunto das imagens e das relações estabelecidas entre as imagens que constituem o capital pensado do homo sapiens, o denominador através do qual é mediada toda compreensão humana - como afirma Silva: "O ser humano é movido pelos imaginários que engendra. O homem só existe no imaginário" (2003, p. 7).

Gilbert Durand é um dos autores que reabilita o imaginário como meio de acesso à "realidade"; imaginário que foi relegado às margens durante a história do conhecimento humano, orientado, quase que exclusivamente, pela racionalidade como método de acesso à verdade e pela palavra como ferramenta eficaz e inequívoca de referencialidade. O movimento teórico de Durand está inserido entre outras diversas teorias que, a partir da segunda metade do século XX, frente à falência dos grandes sistemas explicativos orientados pela razão (aristotélica ou cartesiana) que regeram a Modernidade, procuraram uma reavaliação positiva da 
imagem investigando e sistematizando o imaginário humano, individual e coletivo. O próprio Gilbert Durand (2002) destaca que o contexto intelectual que possibilitou a teoria das estruturas antropológicas do imaginário deve-se, predominantemente, às contribuições da psicanálise de Freud, da antropologia cultural de Lévi-Strauss, da filosofia hermenêutica de Cassirer, da psicologia analítica de Jung e da fenomenologia do imaginário de Bachelard.

\subsection{Explorando as estruturas do imaginário de Gilbert Durand}

Como observamos, para Gilbert Durand, o processo cognitivo humano não apresenta solução direta entre stimulus e reação. Ao contrário, o pensamento humano é uma (re)presentação estabelecida por articulações simbólicas - "o imaginário constitui o conector obrigatório pelo qual forma-se qualquer representação humana.” (2001, p. 41). Além disso, cada imagem que compõe o imaginário surge da relação dialética entre a constituição biopsíquica, a cultura e o meio cósmico humanos, movimento que Durand denominou de "trajeto antropológico" e exemplifica da seguinte forma:

[...] a estrutura de posição fornecida pelo posicionamento do reflexo dominante na vertical necessita a contribuição do imaginário cósmico (a montanha, o precipício, a ascensão...) e do sociocultural (todas as pedagogias da elevação, da queda, do infernal...) sobretudo. Reciprocamente, o precipício, a ascensão e o inferno ou o céu somente adquirem um significado de acordo com a estrutura da posição inata da criança. (2004, p. 91)

Quanto à imagem, para Durand, se apresenta à consciência em diferentes graus de representação, indo desde a cópia fiel da sensação até a condição de apenas assinalar a coisa, sendo a este último caso de representação que os símbolos imaginários pertencem, e é justamente a imagem simbólica que interessa, pois - "o imaginário é construído e expresso através de símbolos" (LAPLANTINE \& TRINDADE, 2001, p. 32). O imaginário, nesse sentido, é "um conjunto de produções, mentais ou materializadas em obras, com base em imagens visuais (quadro, desenho, fotografia) e linguísticas (metáfora, símbolo, relato), formando conjuntos coerentes e dinâmicos" (WUNENBURGER, 2007, p. 11).

Ademais, na imagem simbólica, significante e significado são infinitamente abertos. O significante pode "estender-se por todo o universo concreto, mineral, vegetal, animal, astral, humano, cósmico, onírico ou 
poético" (DURAND, 2004, p. 11-12); enquanto o significado pode aglutinar sentidos divergentes e até antinômicos - o fogo pode representar $\mathrm{o}$ fogo purificador, o fogo sexual, o fogo demoníaco etc. Por isso, o fator que delimitará o tema do símbolo é recorrência da aparição do significado em determinado tempo e/ou espaço ou a redundância dentro do texto analisado, característica que, na sociedade, Maffesoli (2010) chamará de conteúdo "proxêmico" das imagens simbólicas e, nos textos, Burgos (1982) chamará de sintaxe imagética.

Esse potencial de convergência simbólica, na teoria de Durand, foi organizado na forma de estruturas do imaginário, constelações constantes e estruturadas por meio de isomorfismos encontrados no trajeto antropológico constitutivo das imagens. Em relação ao meio cósmico e social, a imagem não possui conteúdo predeterminado, mas certa forma predeterminada pelo arquétipo - "O arquétipo organiza imagens simbólicas, mas sobrepassa as concreções individuais, biográficas, regionais e sociais da formação de imagens. Tem, portanto, um papel mediador" (MELLO, 2002, p. 69). Quanto à constituição do símbolo na cognição humana, Durand observa que "o símbolo é sempre o produto dos imperativos biopsíquicos pelas intimidações do meio" (2002, p. 41).

Desse modo, para sistematizar a convergência das imagens em constelações simbólicas, Gilbert Durand partiu da estrutura biopsíquica humana, buscando na teoria dos gestos dominantes da escola de reflexologia de Betcherev os núcleos organizadores. O isomorfismo percebido entre as imagens foi organizado a partir dos mais primitivos conjuntos sensório-motores que enformam os sistemas de acomodações mais originários na ontogênese humana - o reflexo da posição, da nutrição e da cópula. Nas palavras de Durand:

o aparelho nervoso do recém-nascido e em particular o cérebro [...] parece-nos evidenciar a trama metodológica sobre a qual a experiência da vida, os traumatismos físiológicos, a adaptação positiva ou negativa ao meio virão inscrever os seus motivos e especificar o 'polimorfismo' tanto pulsional como social da infância (DURAND, 2002, p. 47).

O primeiro reflexo, a posição, refere-se à tendência natural do recém-nascido à postura ereta e "coordena ou inibe todos os outros reflexos quando, por exemplo, se põe o corpo da criança na vertical" (DURAND, 2002, p. 48). A posição permite à criança a distinção entre verticalidade $\mathrm{e}$ horizontalidade, e o instinto de se manter na vertical origina uma valorização positiva para o 'em cima' e negativa para o 'embaixo'. Essa dico- 
tomização espacial, consequentemente, valoriza a atitude de 'separar' os opostos, e tal intenção, no imaginário, não se reduz apenas aos elementos que se contrapõem espacialmente, mas se estende até as derivações filosóficas e racionais. Por exemplo, os silogismos aristotélicos, o método cartesiano, o materialismo dialético marxista, entre outros modelos de pensamento, para Durand, são pensamentos construídos a partir da atitude de separar, orientada pelo reflexo posicional. Nesse sentido, a abrangência do conceito de imaginário em Durand organiza em um mesmo movimento imagético, por exemplo, a distinção positiva que se faz entre o céu nas alturas e o inferno nas profundezas e a constituição de um sistema filosófico complexo como o marxismo que, para o autor, situa miticamente "o progresso inelutável da humanidade em três "épocas" consecutivas da revolução, a saber: primeiro a do Pai, depois a do Filho e, por último, a do Espírito Santo, isto é, a época da paz universal por vir.” (2004. p. 47).

É interessante observar que, Mircea Eliade, semelhantemente, também destaca em Marx uma intenção mítica.

Marx retoma e prolonga um dos grandes mitos escatológicos do mundo asiático mediterrânico, a saber, o papel redentor do justo (o "eleito", o "ungido", o "inocente", o "mensageiro"; nos nossos dias, o proletariado), cujos sofrimentos são chamados a mudar o estatuto ontológico do mundo. Com efeito, a sociedade sem classes de Marx e a conseqüente desaparição das tensões históricas encontram seu precedente mais exato no mito da Idade do Ouro, que, segundo múltiplas tradições, caracteriza o começo e o fim da História. Marx enriqueceu este mito venerável de toda uma ideologia messiânica judaico-cristã: por um lado, o papel profético e a função soteriológica que ele atribuiu ao proletariado; por outro, a luta final entre o Bem e o Mal, que pode aproximar-se facilmente do conflito apocalíptico entre o Cristo e o Anticristo, seguido da vitória decisiva do primeiro. É até significativo que Marx resgate, por sua conta, a esperança escatológica judaico-cristã de um fim absoluto da História; distingue se nisso dos outros filósofos historicistas (por exemplo Croce e Ortega y Gasset), para quem as tensões da história são consubstanciais à condição humana e, portanto, jamais poderão ser completamente abolidas. (ELIADE, 1992, p. 168)

A segunda dominante, a nutrição, é um imperativo biológico que "nos recém-nascidos, se manifesta por reflexos de sucção labial e de orientação correspondente da cabeça" (DURAND, 2002, p. 48). Provocada por estímulos externos, valoriza a atitude de 'incluir', da integração do corpo ao outro corpo. 
A terceira dominante, a cópula, para Durand, "seria de origem interna, desencadeada por secreções hormonais e só aparecendo em período de cio" (2002, p. 48). É desencadeada por secreções hormonais no humano adulto, no entanto, já figura anteriormente em várias brincadeiras e jogos rítmicos das crianças, como uma espécie de exercício da sexualidade. Ademais, "Esta rítmica sexual está ligada à rítmica da sucção e há uma anastomose muito possível entre a dominante sexual latente da infância e os ritmos digestivos da sucção" (2002, p. 50); isto é, o segundo e o terceiro reflexo dominante combinar-se-iam em cruzamentos simbólicos. Por isso que os símbolos do engolimento, por exemplo, têm frequentemente prolongamentos sexuais. Nesse ponto, podemos observar que, para Durand, a teoria de Freud restringiu a interpretação das imagens simbólicas à dominante copulativa, tal como é descrito no complexo de Édipo.

Pitta (2005), exemplificando o trajeto, observa que, nos gestos dominantes, encontram-se os schémes da estruturação do imaginário, tendência geral dos gestos que faz a junção entre os reflexos psicobiológicos e as representações, dimensão verbal mais abstrata que corresponde à ação básica de cada regime do imaginário (diurno/dividir, noturno sintético/unir, noturno místico/confundir) - por exemplo, à postura da verticalidade (diurno/dividir) correspondem os esquemas verbais subir e cair; à dominante da nutrição (noturno místico/confundir) correspondem os esquemas verbais descer, possuir, penetrar rumo à intimidade. À tendência dos schémes, soma-se o arquétipo, responsável pela forma desta "intenção fundamental", isto é, imagem primeira de caráter coletivo que representará os schèmes - por exemplo, o esquema verbal subir será representado pelos arquétipos do chefe, do alto, do céu, do cume; os esquemas verbais descer, possuir ou penetrar serão representados pelos arquétipos da mãe, da morada, do centro, do alimento, etc. Por fim, o símbolo constituir-se-á na tradução do arquétipo dentro de um contexto específico, visível nos rituais, nos mitos, na literatura, nas artes plásticas - por exemplo, a Virgem Maria (a mãe), o Monte Olimpo (o cume), Deus (o chefe/ o pai). O exemplo que Pitta (2005, p. 20) oferece para demonstrar o trajeto antropológico é o seguinte: o schème unir (que infere 'proteger') liga-se ao arquétipo da mãe e culmina na imagem simbólica da Virgem Maria na cultura cristã.

Gilbert Durand (2002) ainda divide as estruturas antropológicas do imaginário em dois grandes regimes: o Regime Diurno que "tem a ver com a dominante postural, a tecnologia das armas, a sociologia do soberano mago e do guerreiro, os rituais de elevação e da purificação" (p. 58), e o Regime Noturno que é subdividido em dominantes digestivas, 
"nas quais se subsome as técnicas do continente e do hábitat, os valores alimentares e digestivos, a sociologia matriarcal e alimentadora" (p. 58), e em dominantes copulativas, "nas quais se agrupam as técnicas do ciclo, do calendário agrícola e da indústria têxtil, os símbolos naturais ou artificiais do retorno, os mitos e dramas astrobiológicos." (p. 58).

Ainda há três grandes conjuntos simbólicos, denominados "as faces do tempo", que se ligam diretamente a negatividade da morte: os símbolos teriomórficos (ligados à animalidade), os símbolos nictomórficos (ligados às trevas) e os símbolos catamórficos (ligados à queda). Para Durand, tais grupos simbólicos pertenceriam ao Regime Diurno; para Strongoli (2005), podem ser posicionados a parte dos regimes, visto que são originados de fontes empíricas revestidas de realismo sensorial, isto é, surgem da observação do mundo exterior e são representados nas figuras dos animais, das trevas e da queda. Mas o fundamental é observar que todo movimento imaginário dos dois regimes será para vencer a morte representada pelos símbolos catamórficos, teriomórficos e nictomórficos. No regime diurno, por exemplo, erguem-se esquemas, representados pelas imagens do cetro (símbolo ascensional por excelência) e do gládio (símbolo diairético por excelência), que serão as armas de combate contra a angústia diante do inexorável fluir temporal. Desse modo, o esquema ascensional, o arquétipo da luz uraniana e o esquema diairético serão as representações pontuais contra os símbolos catamórficos (queda), nictomórficos (trevas) e teriomórficos (animalidade).

\section{A poesia a partir do imaginário}

A teoria das estruturas antropológicas do imaginário possibilita caminhos instigantes e reveladores na interpretação dos textos literários, visto que aponta para estruturas composicionais e sentidos não encontrados nas leituras sociais, estilísticos e psicológicos, tradicionalmente incorporadas às interpretações das obras literárias.

No poema abaixo, retirado da obra Em algum parte alguma (2010) de Ferreira Gullar, podemos observar algumas das possibilidades da teoria do imaginário. 


\section{ANOITECER EM OUTUBRO}

A noite cai, chove manso lá fora

meu gato dorme

enrodilhado

na cadeira

Num dia qualquer

não existirá mais

nenhum de nós dois

para ouvir

nesta sala

a chuva que eventualmente cai

sobre as calçadas da rua Duvivier.

(GULLAR, 2010, p. 65)

No poema, descreve-se uma noite chuvosa de outubro, da qual participam o eu-lírico e seu gato. A residência na rua Duvivier no Rio de Janeiro, a presença de um gato como animal doméstico e o pequeno conhecimento que os leitores possuem do poeta Ferreira Gullar podem resultar, facilmente, na construção da imagem de um eu-lírico homem idoso, que vive só com seu animal doméstico e, melancolicamente, observa a noite chuvosa e reflete sobre o caminho inexorável que a vida percorre até a morte - finitude que alcançará a ele e ao seu gato. No entanto, supondo que esse seja mesmo o cenário que possivelmente um leitor de Ferreira Gullar infira do poema em sua interpretação, a presença da morte instala-se calmamente nos versos, e não há nenhum desespero ou desamparo frente à inevitabilidade da finitude. Ao contrário, há uma calma aceitação dos desígnios do destino humano.

A teoria do imaginário de Durand, nesse ponto, nos apresenta um caminho instigante para a interpretação dessa contradição entre a tranquilidade do eu-lírico e a inevitabilidade da morte através da exploração das imagens presentes no poema.

A primeira imagem que aparece no poema é a "noite", presente no título no verbo "anoitecer" e no primeiro verso "A noite cai". A noite é um símbolo nictomórficos que se relaciona a um temor primordial dos riscos naturais que o período noturno representava aos os primeiros hominídeos - visto que, desprovidos de garras, mandíbulas fortes ou demais adjuvantes para a autodefesa, tornavam-se alvo fácil aos predadores noturnos. Além disso, diversas pedagogias e formas de socialidade humana apontam à relação entre as trevas e a depressão, o pecado, o julgamento, 
etc.; assim como, a noite também infere certa analogia com o movimento caótico, a agitação desordenada, o sadismo dentário, entre outros símbolos teriomórficos que podem ser observados em diversos mitos que descrevem a aparição de monstros infernais que se apoderam dos corpos e das almas durante o período noturno. Por último, a noite ainda se alinha à imagem da cegueira que, por sua vez, pode inferir à perda da razão, aproximação percebida entre a figura inquietante do cego e do louco.

A segunda imagem presente no poema é a queda, inferida do núcleo verbal do verso "A noite cai". A queda é símbolo catamórfico relacionado à dominante postural, originada do reflexo da sensibilização imediata do recém-nascido para a verticalidade - "Para o bípede vertical que somos, o sentido da queda e da gravidade acompanha todas as nossas primeiras tentativas autocinéticas e locomotoras" (DURAND, 2002, p. 113). No imaginário, a queda transforma-se em signo de punição e de pecado.

Desse modo, as duas primeiras imagens do poema se remetem à presença negativa da morte, manifestada na imagem das trevas e da queda, e adiantam a remissão literal à morte que ocorre no segundo verso. No entanto, como observamos, o poema trata o tema da morte não a partir do desamparo, mas a partir da calma aceitação do destino. Nesse ponto, é interessante observar que as próximas imagens do poema estabelecerão, justamente, esse movimento de eufemização da face terrível da morte.

A terceira imagem, "chove manso lá fora", transforma a imagem terrificante da queda em descida lenta, delicado processo de eufemização que afasta a face negativa do schème "cair". Gilbert Durand também observa que a descida infere sempre um ingresso sinestésico e visceral, marcado pela lentidão e, sobretudo, pelo calor aconchegante da interioridade, oposto à exterioridade e agressividade da queda. E é justamente esse movimento rumo à intimidade que observamos na imagem "meu gato dorme", isto é, a imagem do animal doméstico auxilia na transformação da queda em descida íntima e aconchegante. Além disso, o posicionamento do gato, "enrodilhado", contribui ao imprimir no poema a sensação térmica do calor aconchegante citado por Durand. Nesse sentido, a noite é eufemizada, "A ameaça das trevas inverte-se numa noite benfazeja" (DURAND, 2002, p. 235), e correlaciona-se à intimidade da descida. Nesse movimento, também ocorre a inversão da exterioridade apontada pela chuva que cai fora para a interioridade da morada, suscitada através da imagem do animal doméstico, e a morada, como aponta 
Durand, representa refúgio íntimo, isomórfico ao microcosmos do corpo humano que é o ventre materno.

Esses símbolos de inversão e de intimidade pertencem às estruturas místicas do imaginário, segunda estrutura da representação e primeira do Regime Noturno da imagem na teoria de Durand. A palavra mística significa, para o autor, inclusão - "a vocação de ligar, de atenuar as diferenças, de subutilizar o negativo pela própria negação é constitutiva deste eufemismo levado ao extremo a que se chama antífrase." (DURAND, 2002, p. 273).

Strongoli (2005), quanto à modalidade mística, observa semelhantemente que as imagens perseveram em um tema, desdobrando-o por metáforas, realismo sensorial e miniaturizações até destituí-lo da agressividade e do perigo, privilegiando a profundidade, a intimidade, o fechamento ou o retorno ao centro; enfim, ação assimiladora que confunde, une, estabelece analogias, atenua diferenças e nega o que é negativo por meio de processos eufêmicos e antifrásticos.

Dessa forma, ocorre no poema a inversão da potência terrificante da imagem da morte impressa na queda e na noite através do schéme do engolimento que, sobredeterminado pela dominante da digestão, realiza um perfeito isomorfismo na troca dos valores negativos da noite e da queda pelas imagens positivas engendradas pela descida íntima e aconchegante. Assim, observamos no poema um movimento de imagens pertencentes ao Regime Noturno do imaginário, regidas pela dominante digestiva - "com seus derivados adjuvantes cenestésicos, térmicos e os seus derivados táteis, olfativos, gustativos" (DURAND, 2002, p. 443) -, em direção a eufemização da morte, preparando o terreno para a exposição racional da finitude e para a aceitação do destino por parte do eu-lírico, e decorrente aceitação desse sentido por parte do leitor.

\section{Considerações finais sobre poesia e imaginário}

A riqueza conceitual da teoria do imaginário de Gilbert Durand possibilita leituras diversas e enriquecedoras das obras literárias. Como observamos no poema "ANOITECER EM OUTUBRO" de Ferreira Gullar, há toda uma preparação imagética para a abordagem do tema da morte que só pode ser percebida a partir da análise das estruturas do imaginário. A inversão dos símbolos da queda e das trevas para a descida aconchegante antecede a própria menção literal ao conteúdo da morte e, de certa forma, prepara o leitor para a aceitação da forma pela qual o eu-lírico apresenta o tema. 
Para nós, um dos principais pontos positivos da teoria das estruturas antropológicas do imaginário é possibilitar a reintrodução, de forma muito proficiente, da análise das imagens nas interpretações literárias. Além disso, a teoria permite, mesmo em um poema de pequena extensão como o poema de Ferreira Gullar aqui analisado, encontrar relações de sentido entre homem e realidade exterior que estão profundamente enraizadas na constituição biopsíquica do homo simbólicus e em constante analogia com o meio cósmico e social - relações que dificilmente poderiam ser observadas a partir de outros pressupostos teóricos.

\section{POETRY AND THE ANTHROPOLOGYC STRUCTU- RES ON GILBERT DURAND IMAGINARY: reading of a Ferreira Gullar poem}

\section{ABSTRACT}

Facing the failure of the great explicative systems guided by reason (Aristotelian or Cartesian) that guided the Modernity, from the second half of the twentieth century, many theories arose with the purpose of searching for a positive reevaluation of the image, investigating and systemizing the human, individual and collective, imaginary, formerly excluded from the knowledge access possibilities. The figurative structuralism of Gilbert Durand, on this context, brings to the intellectual scenery a consistent perspective, instigate and profitable to the imaginary studies. On this article, we intend to introduce some of the assumptions on Gilbert Durand theory, as well as a general panorama of the "imaginary anthropology structures". Furthermore, from the reading of a Ferreira Gullar poem according to Durandian theory, we expose some of the possibilities that the imaginary investigation offers to literary critique. KEYWORDS: Imaginary. Poetry. Gilbert Durand. Ferreira Gullar. 


\section{REFERÊNCIAS}

ADORNO, Theodor W. Teoria Estética. Trad. Artur Morão. Lisboa: Edições 70, 1993. BURGOS, Jean. Pour une poétique de l'imaginaire. Paris: Editions du Seuil, 1982.

CANDIDO, Antonio. Literatura e sociedade: estudos de teoria e história literária. São Paulo: T. Queiroz, 2000.

COMPAGNON, Antoine. O demônio da teoria. Belo Horizonte: EdUFMG, 2010. DURAND, Gilbert. As Estruturas Antropológicas do Imaginário: introdução à arqueologia geral. São Paulo: Martins Fontes, 2002. . Campos do imaginário. Lisboa: Piaget, 2001.

- O imaginário: ensaio a cerca das ciências e da filosofia da imagem. Rio de Janeiro: Difel, 2004.

ELIADE, Mircea. Mito do eterno retorno. São Paulo: Mercuryo, 1992.

GULLAR, Ferreira. Em alguma parte alguma. Rio de Janeiro: José Olympio, 2010.

LAPLANTINE, François; TRINDADE, Liana. O que é imaginário. São Paulo: Brasiliense, 2001.

MAFFESOLI, Michel. No fundo das aparências. Petrópolis, RJ: Vozes, 2010.

MARX, K. Contribuição à crítica da economia política. São Paulo: Martins Fontes, 1983.

MELlo, Ana Maria Lisboa de. Poesia e imaginário. Porto Alegre: EDIPUCRS, 2002.

PITTA, Danielle Perin Rocha. Iniciação à teoria do imaginário de Gilbert Durand. Rio de Janeiro: Atlântica Editora, 2005.

SILVA, Juremir Machado. As tecnologias do imaginário. Porto Alegre: Sulina, 2003.

STRONGOLI, Maria Thereza de Queiroz Guimarães. Encontros com Gilbert Durand: Cartas, Depoimentos e Reflexões sobre o imaginário. in: PITTA, Danielle Perin Rocha (org.). Ritmos do Imaginário. Recife: Ed. Universitária da UFPE, 2005.

WUNENBURGER, Jean-Jacques. O imaginário. Trad. Maria Stela Gonçalves. São Paulo: Edições Loyola, 2007.

Recebido em: 01/09/2016

Aceito em: 06/06/2017 